\title{
Côinparison of Effects of Context-Based Learning and Cooperative Learning on Professional Behavior and Critical Thinking of Anesthesiology Students
}

\author{
Fozieh Bakhsha $^{1}$, Solmaz Halakou*1, Seyyed Yaquob Jafari ${ }^{1}$, Zahra Yousefi ${ }^{1}$, Zahra Mehrbakhsh ${ }^{2}$
}

1. Department of Anesthesiology, Faculty of Paramedicine, Golestan University of Medical Sciences, Gorgan, Iran

2. Department of Biostatistics and Epidemiology, Faculty of Health, Golestan University of Medical Sciences, Gorgan, Iran

\begin{abstract}
Background and objectives: Promoting and influencing the formation of professional behavior is one of the most challenging issues in education. The purpose of this study was to compare effects of context-based learning (CBL) and cooperative learning on professional behavior and critical thinking of anesthesiology students.

Methods: This was a semi-experimental study that was conducted on 42 third and fifth semester anesthesiology students who were divided into a CBL group $(n=21)$ and a collaborative learning group $(n=21)$. Data were collected before the intervention and one week and a month after the intervention using a questionnaire designed by Goze et al. and the Ricketts' Critical Thinking Disposition Inventory. The collected data were analyzed with SPSS (version 16) using the generalized estimation equation method, the Chi-square test, independent T-test and the MannWhitney U test. A p-value of less than 0.05 was considered statistically significant.

Results: After the intervention, the mean score of professional behavior and critical thinking did not differ significantly between the two groups $(\mathrm{P}>0.05)$, but time had a significant impact on the mean score of professional behavior and critical thinking of the students $(\mathrm{P}<0.05)$. Moreover, the mean score of critical thinking increased over time in both groups and then remained constant. The mean score of professional behavior increased over time in both groups but decreased later in the CBL group.

Conclusion: The implementation of both learning approaches is equally effective in improving students' attitude toward professional behavior and critical thinking.

Keywords: Education, professional behavior, critical thinking, cooperative learning, context-based learning

\section{$\begin{array}{lll}\text { Received: 2019/03/10 } & \text { Revised:2019/04/15 } & \text { Published:2019/07/31 }\end{array}$}

*Correspondence: Solmaz Halakou, Department of Anesthesiology, Faculty of Paramedicine, Golestan University of Medical Sciences, Gorgan, Iran.

Tel: +98-9118665823

Email: solmazhalakou@gmail.com
\end{abstract}




\section{INTRODUCTION}

When training human resources, in addition to the occupation-specific knowledge and skills, one must pay particular attention to the development and strengthening of values, attitudes, ethical norms, social skills and other characteristics that shape professional behaviors. Creating and influencing the formation of professionalism is a challenging issue in education $(1,2)$. The main objective of medical sciences education is the development of competence, professional behavior, decision-making and problem solving skills and self-efficacy, which themselves are influenced by the ability to practice critical thinking (3). The need to address critical thinking in medical sciences education is consistent with the growing demand for expansion of critical thinking skills for problem solving and decision making (4).

Despite the expansion of educational programs, this area is still facing many shortcomings that emphasize the need for development of novel educational programs (5). Traditional and passive methods of medical education can be tiresome and reduce attention, motivation and learning efficacy. In recent years, emphasis has been put on active learning and creative thinking in medical education (6).

To convey concepts, educational messages and the skills required by the learners, it is essential to create opportunities that enable learning through practical and actual experiences, not just theoretical endeavor (7).Context-based learning (CBL) is an educational approach that employs problemsolving based learning, in which real and clinical experiences are used in the educational environment. The method incorporates several real-life situations as the basis of learning that allows the learner to analyze the situation and to search for concepts accordingly, which enables the students to develop critical thinking skills (8).

Another learner-centered educational approach is cooperative learning, in which learners work together in small groups to achieve a common goal (9). In this method, students create a new learning environment, learn how to process new information and gain a fresh learning experience by the end of the course $(10,11)$. Lin (2013) conducted a study to compare individual learning and cooperative learning on critical thinking, knowledge acquisition and proficiency of nurses (12). Higher education is one of the most important factors that shape the ethical and professional character of students. Despite the emphasis on the necessity of teaching professional behavior and strengthening critical thinking, there are still major weaknesses and challenges regarding the quality of education. Therefore, we conducted a study to compare the two methods of CBL and cooperative learning on the attitude of anesthesiology students towards professional behavior and critical thinking.

\section{MATERIALS AND METHODS}

This was a semi-experimental study that was conducted in 2017, on 42 third and fifth semester students of anesthesiology who were divided into a CBL $(n=21)$ and collaborative learning $(n=21)$ groups. Data were collected using a questionnaire designed by Goze et al. (13) consisting of 27 items that were scored based on a 5-point Likert scale (ranging from never to usually). In order to evaluate critical thinking, the Ricketts' Critical Thinking Disposition Inventory was used. The tool includes 33 items on three domains of innovation (11 items), maturity (9 items) and engagement (13 items) that are scored based on a 5-point Likert scale (strongly disagreestrongly agree) (14-16).

Those unwilling to continue participating in the study were excluded from the study. Written consent for participation was obtained from all subjects after explaining the research goals in detail. Then, a demographic questionnaire was given to all subjects. The same person conducted the training for both groups. Content of the sessions was professional behavior in the workplace for 
both groups. CBL training was carried out in four stages:

1. Situation test: Four functional scenarios on challenges of professional behavior in the operating room and in the classroom were given to the students. The students were asked to explore the situation with emphasis on the role of anesthesiologists in patient's health status. This session of CBL lasted 90 minutes.

2. Self-learning: At the end of the first session, students were asked to search in the electronic libraries using the following keywords: professional behavior and anesthesiology. This session was held one week after the first session and lasted 90 minutes.

3. At this stage, the students were asked to give a brief summary (5-10 minutes) of what they had learnt from the electronic search. At this stage, the instructor asked questions about the student's initial perspective and how it has changed after the study, thus encouraging students to connect the new concepts to their old information.

4. Reflection: At the end of the second session, a 20-minute group discussion was held as the last step of the CBL approach.

In order to conduct the cooperative education method, the students were assigned to three groups of five and a group of six. In this method, the content of the curriculum was provided to the groups as a booklet on professional behavior (9). The subjects were asked to study the booklet for 20 minutes, then share their moral experiences in the classroom and discuss the challenges of professional behavior. The session lasted 120 minutes.

Posttest data were gathered a week after the last session and one month after the intervention using the data collections tools. The collected data were analyzed in SPSS software package (version 16) using ShapiroWilk test, Chi-square test, independent T-test and Mann-Whitney $U$ test and generalized estimating equation (GEE) method, at statistical significance of 0.05 .

\section{RESULTS}

The mean age of students was $21.33 \pm 0.97$ years in the CBL group and $21.25 \pm 0.84$ years in the cooperative learning group. There was no statistically significant difference in the mean age of the two groups $(\mathrm{P}=0.74)$. The mean total score of students was $16.03 \pm 0.8$ in the CBL group and $15.98 \pm 0.72$ in the cooperative learning group. The students mean total score did not differ significantly between the two groups $(\mathrm{P}=0.82)$. The two groups were also matched in terms of gender and interest in the field.

Based on the results of the GEE method, the mean score of professional behavior and critical thinking did not differ significantly between the two groups ( $P>0.05)$, but time had a significant impact on the mean score of professional behavior and critical thinking of the students $(\mathrm{P}<0.05)$. In addition, the grouptime interaction had no significant impact on the mean score of professional behavior and critical thinking (Table 1).

Table 1. Results of the GEE method of assessing effects of the interventions on professional behavior and critical thinking

\begin{tabular}{|c|c|c|c|c|c|c|}
\hline \multicolumn{4}{|c|}{ Professional behavior } & \multicolumn{3}{c|}{ Critical thinking } \\
\hline Parameter & EST & Std. Error & P-value & EST & Std. Error & P-value \\
\hline Intercept & 107.29 & 4.60 & $<0.001$ & 120.71 & 4.29 & $<0.001$ \\
\hline Group & 8.93 & 6.32 & .158 & 3.05 & 5.67 & .590 \\
\hline Time & 5.61 & 1.38 & .009 & 5.41 & 2.44 & .027 \\
\hline Interaction & -4.32 & 2.98 & .147 & -3.08 & 2.86 & .282 \\
\hline
\end{tabular}


Journal of Clinical and Basic Research (JCBR). 2019; 3(2): P 14-20.

According to the results, the mean score of critical thinking increased over time in both groups and then remained constant. The mean score of professional behavior increased over time in both groups but decreased later in the CBL group (Table 2).

Table 2. The mean score of critical thinking and professional behavior before, right after and one month after the interventions in the study groups

\begin{tabular}{|c|c|c|c|c|}
\hline Variable & \multicolumn{1}{|c|}{ Groups } & \multicolumn{3}{c|}{ Testing time } \\
\hline \multirow{2}{*}{\begin{tabular}{c} 
Critical thinking \\
\cline { 2 - 5 }
\end{tabular}} & Context-based learning & $126.23 \pm 11.14$ & $130.17 \pm 17.34$ & $130.0 \pm 7.60$ \\
\cline { 2 - 5 } & Cooperative learning & $125.84 \pm 11.78$ & $135.89 \pm 15.20$ & $135.42 \pm 18.81$ \\
\hline \multirow{2}{*}{$\begin{array}{c}\text { Professional } \\
\text { behavior }\end{array}$} & Context-based learning & $117.11 \pm 11.27$ & $120.11 \pm 15.19$ & $119.29 \pm 10.58$ \\
\cline { 2 - 5 } & Cooperative learning & $114.10 \pm 15.65$ & $118.42 \pm 19.51$ & $124.31 \pm 17.37$ \\
\hline
\end{tabular}

\section{DISCUSSION}

The purpose of this study was to compare the effects of $\mathrm{CBL}$ and cooperative learning on the professional behavior and critical thinking of anesthesiology students. The results showed that both educational methods were effective on the professional behavior and critical thinking of the students, and there was no notable difference between the two methods. In 2009, Van Mook conducted a study entitled "Education and learning professional behavior in action", and concluded that the key conditions of learning professional behavior are providing experiences and evaluation of results in the curriculum (17). In a study by Davis, members of the occupational therapy faculty believed that ethical behavior, cultural competence, respect for themselves and others, self-awareness and leadership are the most important behaviors that should be assessed in students (18).

In this study, time had a significant impact on the mean score of professional behavior in students. In other words, in the different stages of professional behavior assessment, both learning approaches were able to increase the mean score of professional behavior and critical thinking. This finding is in line with the results of two previous studies $(19,20)$. In 2013, Lin reported that cooperative learning has been a more effective approach compared to individual learning (12). Cooperative learning is based on the cognitive development and behavioral learning theory. In addition, evidence suggests that group work can improve students' educational outcomes (11).

In the present study, students reported that cooperative education alongside traditional education methods, such as lecturing, could be very effective, particularly in promoting learning motivation. Although the results of the present study and similar studies confirm the considerable advantage of cooperative education over other learning approaches (21), this method is less popular among nursing and midwifery students as they show more tendency toward the traditional lecture method (22).

The mean score of professional behavior increased in the cooperative learning group and decreased in the CBL group over time. In 
a study by Manzari et al., CBLwas significantly more effective than lecturebased learning in increasing the knowledge, attitude and practice scores of nurses about their role in organ donation process (23). In general, $\mathrm{CBL}$ is more effective in improving clinical practice. However, moving from a traditional approach to a CBL-based curriculum is challenging and requires simultaneous philosophical changes, curriculum planning and proper performance assessment. In 2012, Williams et al. compared effects of CBL and problem-based learning on the growth of professional performance of nurses in Canada, and found that CBL could promote self-awareness in their subjects (24). Although lecturing is the most common method used in Iran's education system, we did not implement this method in our study since numerous studies have demonstrated that traditional methods are usually ineffective, encourage passive learning and do not take into account individual differences, learners' needs, problem solving, creative thinking and other higher-level cognitive skills (4).

In this study, the modern educational methods were effective in promoting critical thinking in students. Integration of new teaching approaches in education of nursing students can facilitate critical thinking. Burns et al. (2013) reported critical thinking as a fundamental principle of improving the learning process in nurse anesthesia education (25). Garcha and Kumar (2015) reported that cooperative learning is more effective than the traditional methods for improving critical thinking in high school students (26).

The limited time of the study was a limitation of the present research because behavior change, particularly at performance level, is a time-consuming process.

\section{CONCLUSION}

The implementation of CBL and cooperative learning approaches is effective in improving students' attitude toward professional behavior and critical thinking, with no significant difference between the two educational methods.

\section{ACKNOWLEDGEMENTS}

The authors would like to thank the authorities of the Golestan University of Medical Sciences and all those who participated in the study.

\section{DECLARATIONS \\ Funding}

This article has been extracted from a research project supported by the Golestan University of Medical Sciences, Iran.

\section{Ethics approvals and consent to participate}

Oral consent was obtained from the subjects. The study received approval from the ethics committee of the GolestanUniversity of Medical Sciences (code: IR.goums.REC.1395.186).

\section{Conflict of interest}

The authors declare that there is no conflict of interest regarding the publication of this article.

\section{REFERENCES}

1. Kim-Godwin YS, Baek HC, Wynd CA. Factors influencing professionalism in nursing among Korean American registered nurses. Journal of Professional Nursing. 2010;26(4):242-9. [DOI:10.1016/j.profnurs.2009.12.007]

2. Hisar F, Karadağ A, Kan A. Development of an instrument to measure professional attitudes in nursing students in Turkey. Nurse Education Today. 2010;30(8):726-30. [DOI:10.1016/j.nedt.2010.01.013]

3. Mullen M. Examining patterns of change in the critical thinking skills of graduate nursing students. J Nurs Educ. 2009;48(9):310-18. [DOI:10.3928/01484834-20090515-03]

4. Khatoni A, Nayery ND, Ahmady F, Haghani H. Comparison the effect of Web-based Education and Traditional Education on Nurses Knowledge about Bird Flu in Continuing Education. Iranian journal of medical education. 2011;11(2):19[persian]

5. Stone R, Cooper S, Cant R. The value of peer learning in undergraduate nursing education: a 
systematic review. ISRN nursing. 2013;2013:110. [DOI:10.1155/2013/930901]

6. Adib-Hajbaghery M, Rafiee S. Comparing the Effectiveness of Group Discussion and Lecture Methods on the learning of medical sciences students: A Review Study. Iranian Journalof Medical Education. 2016;16:53-62[persian].

7. Meyer K, Bjørk IT. Change of focus: from intensive care towards organ donation. Transplant International. 2008;21(2):133-9.

8. HassanpourDehkordi A, Masoudi R. Effect of Application Context Based Learning (CBL) and Traditional Learning on the Behavior, Attitude, Learning and Critical Thinking of Nursing Students Integration of Theory and Practice. $\mathrm{J}$ of Jondishapour education development. 2015 6(3):198-205[persian].

9. Momeni Danaei S, Zarshenas L, Oshagh M, Khoda O, Maryam S. Whichmethod of teaching would be better cooperative or lecture? Iranian journal of medical education. 2011;11(1):2431 [persian].

10. Silva B, Madeira RN, editors. A study and a proposal of a collaborative and competitive learning methodology. IEEE EDUCON 2010 Conference; 2010: IEEE. [DOI:10.1109/EDUCON.2010.5492466]

11. Megahed MM, Mohammad FA. Effect of cooperative learning on undergraduate nursing students' self-esteem: A quasi-experimental study. Journal of Nursing Education and Practice. 2014;4(11):1[persian].

[DOI:10.5430/jnep.v4n11p1]

12. Lin Z-C. Comparison of technologybasedcooperative learning with technology-based individual learning in enhancing fundamental nursing proficiency. Nurse education today. 2013;33(5):546-51.

[DOI:10.1016/j.nedt.2011.12.006]

13. Goz F, Geckil E. Nursing students professional behaviors scale (NSPBS) validity and reliability. Pak J Med Sci. 2010;26(4):938-41.

14. Ricketts JC. The efficacy of leadership development, critical thinking dispositions, and student academic performance on the critical thinking skills of selected youth leaders: University of Florida; 2003.

15. Khandaghi MA, Pakmehr H, Amiri E. The status of college students' critical thinking disposition in humanities. Procedia-Social and Behavioral Sciences. 2011;15:1866-9[persian]. [DOI:10.1016/j.sbspro.2011.04.017]

16. Seamon A. The development of youth leadership life skills including critical thinking dispositions as a result of commercial dairy exhibition: Doctoral dissertation, uga.; 2010

17. Van Mook WN, van Luijk SJ, de Grave W, O'Sullivan H, Wass V, Schuwirth LW, et al. Teaching and learning professional behavior in practice. European journal of internal medicine. 2009;20(5):e105-e11.

[DOI:10.1016/j.ejim.2009.01.003]

18. Davis DR. Assessment of Professional Behavior in Students: Thoughts and Opinions of Occupational Therapy Faculty: West Virginia University; 2015.

19. Abdoli S, Khajeh Ali T. Compression the effect of clinical concept mapping \& nursing process in developing nursing students' critical thinking skills. Iranian Journal of Medical Education. 2012;11(9):1420-9. [persian]

20. Esmaeili R, Izadi A, Esmaeili M, Omidi K. Assessing the effect of Critical thinking education on caring process of nursing students. Modern Care Journal. 2011;8(1):1-6[persian].

21. Mousavi MS, Mahmoudi M, Pou DH, Asgari P. Comparison of Problem Solving and Participatory Teaching Methods on Clinical Learning, Anxiety, and Satisfaction of Nursing Students in Arak University of Medical Sciences, Iran. 2018;7(1):41-50. [persian]

22. Azizzadeh Forouzi M, Mohammad Alizadeh S, Heidarzadeh A. Viewpoints of Nursing and Midwifery Students Toward Desirability of Collaborative Learning in the English Language Course. Journal of Nursing Education. 2016;5(5):37-42. [persian] [DOI:10.21859/jne05056]

23. Manzari Z, Karimi Moonaghi H, Masoumian Hoseini S, Behnam Vashani H, Khaleghi I 
Journal of Clinical and Basic Research (JCBR). 2019; 3(2): P 14-20.

24. Comparing the effect of tow educational methods ( Contexed based learning and lecture) on nurses konwlege, attitude and practice about nurses role in organ donation process. The Journal of Urmia Nursing and Midwifery Faculty. 2015;13(9):758-71.

25. Williams B, Spiers J, Fisk A, Richards L, Gibson B, Kabotoff W, et al. The influence of an undergraduate problem/context based learning program on evolving professional nursing graduate practice. Nurse Education Today. 2012;32(4):417-21.

[DOI:10.1016/j.nedt.2011.03.002]

26. Burns SM, Mendel S, Fisher R, Cooper K, Fisher M. Critical Thinking inNurse Anesthesia Education: A Pilot Study. Journal of Curriculum and Teaching. 2013;2(1):83. [DOI:10.5430/jct.v2n1p83]

27. Garcha PS, Kumar K. Effectiveness of cooperative learning on critical thinking dispositions of secondary school students. 2015;3(1): 55-62 [DOI:10.15415/iie.2015.31005] 